\title{
Voices from different cultures: Foundation Phase students' understanding across borders
}

\begin{abstract}
From "How was your day?" to "Remember the time we ...", we use stories as a way to share our experiences, understandings and concerns with others. Stories extend our knowledge and understanding of other people and situations, other cultures and languages by including the emotional expressions of factual information. When so much of family and community life in South Africa remains insular and disconnected from other cultures, other languages and other belief systems, stories can extend boundaries beyond our single perspectives and experiences to the varying perspectives of others. This becomes particularly important for teachers of young children who may have very different life experiences from those of the children they teach. In this project, we examined storytelling as a way to cross-cultural boundaries and of harnessing the diverse worlds of South African citizens pedagogically. We asked fourth year students in a Foundation Phase teacher education programme to identify a person from a different cultural and linguistic group; and to have that person share a story with them to discover how the experience of listening to stories from different cultures, languages, and belief systems might influence their attitudes towards teaching children with those characteristic differences.
\end{abstract}

Keywords: emotional expressions, single perspectives, storytelling, cross-cultural boundaries

Teresa Harris, University of Pretoria. E-mail: harristt@jmu.edu.

Annalie C. Botha, University of Pretoria. E-mail: ac.botha@up.ac.za.

South African Journal of Childhood Education | 2011 1(2): 81-91 | ISSN: 2223-7674 |๑UJ
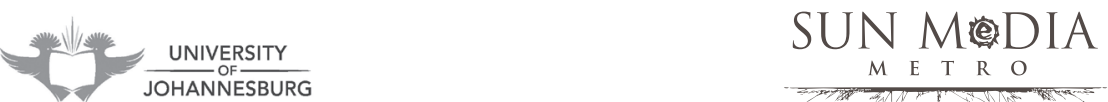


\section{Introduction}

From "How was your day?" to "Remember the time we ...", we use stories as a way to share our experiences, understandings and concerns with others. Stories extend our knowledge and understanding of other people and situations, other cultures and languages by including the emotional expressions of factual information:

[...] a story carries information about how things work and what meanings events have. In addition, stories are told to someone... by someone... who recounts the events and often presumes to know what the characters are thinking. A story also contains information about presumed intention and motivation as well as a sense of audience, of who is looking in on events. Finally, a story by its very nature resists singular interpretation [...] A story captures nuance, indeterminacy and interconnectedness in ways that defy formalistic expression and expand the possibilities for interpretation and understanding (Doyle \& Carter, 2003, p. 130).

When so much of family and community life in South Africa remains insular and disconnected from other cultures, other languages and other belief systems, stories can extend boundaries beyond our single perspectives and experiences to the varying perspectives of others. This becomes particularly important for teachers of young children who may have very different life experiences from those of the children they teach. In this project, we examined storytelling as a way to cross cultural boundaries and of harnessing the diverse worlds of South African citizens pedagogically. We asked fourth year students in the Foundation Phase teacher education programme to identify a person from a different cultural and linguistic group from themselves, and to have that person share a story with them to discover how the experience of listening to stories from individuals of different cultures, languages, and belief systems might influence their attitudes towards teaching children with those characteristic differences.

\section{Literature review: A tale of storytelling}

Benjamin (2006) pointed out that we are all storytellers and stories are a part of our past, as well as our present day life experiences. Stories from our grandmother's knee, as well as from our culture, help to guide and define our identities as members of a family and cultural group, transmitting the cultural knowledge and wisdom that have helped us to survive over time. Stories structure our reality according to cultural norms, values and expectations.

Stories also serve to examine and express our own unique life experiences by giving voice to our individual identities. As we tell stories, we process events of the day, reconnect to our past, or move into the future. Our stories allow us to reflect on our values and beliefs at different points in our personal timelines. In this sense, our stories are not static, but serve as a tool of communication that allows us to "question or problematise the taken-for-granted habits and institutions of performing narrative" (Langellier \& Peterson, 2004, p. 5). Actually hearing ourselves as storytellers, and seeing the reactions of our stories reflected in our listeners, can trigger new ways of thinking about the events we recount. Removed from the immediate time and place, in which 
the story occurs, we can step back to re-view the story line itself, and in the company of the listeners who react to what we are telling, we may be affirmed or challenged to reconsider our own interpretations of the accounts we narrate. The personal story we tell can serve as "a powerful means of becoming aware of the taken-for-granted arrangements and constraints of one's own culture” (Luwisch, 2001, p. 134).

However, the significance of storytelling comes in the experience of sharing it with other people. Through expressive language and sensory imagery, the storyteller attempts to admits other into her world by "neutralising the otherness and strangeness" (Luwisch, 2001, p. 134) while at the same time, listeners attempt to connect with the story and its teller. Through the platform of storytelling, individuals from dissimilar cultures can share aspects of their life-worlds in ways that inform, enlighten, and illuminate so as to better appreciate the perspectives of the other (Sax, 2006). However, the ability to appreciate the differences between storyteller and listener is dependent on the willingness of both to learn from and about the other. This can be particularly powerful for marginalised people who have the opportunity to claim their own voices and share them with others who want to hear what they have to say. However, if the listener attends with sensitivity to the stories shared by a storyteller who represents a position of cultural and linguistic difference, the listener benefits in that she becomes better able to appreciate the other person. This is particularly important for teachers of learners whose life-worlds are significantly different from their own, and who teach in settings where there is great diversity among the learners themselves.

Within the classroom setting, teachers must first build relationships with their students as unique individuals who are living and learning together as a community. This is particularly important in classrooms of teachers and learners who are different from one another culturally. Appreciating one's own stories as a way of understanding oneself, can lead to a greater sensitivity towards others and the stories they have to share. In studies reported by Luwisch (2001), teachers who attended to their own stories and integrated them into their curriculum became more adept at engaging with their students' concerns, pointing to the critical importance of story, as a way to personally connect with learners.

The personal connection that develops through storytelling comes through listening to another person, especially when the other person is in a marginalised or less powerful position, as is often the case with learners in classrooms. Ball (2006) points out that the pedagogical implications of listening to the narratives of students includes getting to know students as individuals, actively engaging them in lessons, holding high expectations for their performance, and connecting content to students' lived experiences. She goes on to state that as

[...] developing teachers listen to the narrative voices of those living and working in impoverished or under-resourced schools, they can come to hear about the characteristics that this population considers important in an effective teacher $[\ldots .$.$] they can begin to hear what the students are saying about how they want$ their education to challenge them to become critical thinkers [...] they can begin to hear their aspirations (Ball, 2006, p. 43-44). 
In their work to develop a culturally sensitive curriculum in their teacher education class, Percival and Black (2000) explored the use of stories and folktales as a method of organising their own teaching. Working from Nieto's definition of culture as

$[\ldots]$ the ever-changing values, traditions, social and political relationships, and worldview shared by a group of people bound together by a combination of factors that can include a common history, geographic location, language, social class and/or religion (Percival \& Black, 1992, p. 111),

they conceptualised the development of a culturally sensitive curriculum as a process of discovery where students learn to respect the differences of others. In ways similar to the work of Sommer and others (2009) who used stories to "transcend cultural boundaries", within counselling supervision settings, this study is part of an ongoing examination of how pre-service teachers traverse cultural boundaries through storytelling.

\section{Theoretical and conceptual framework of research}

Because we are preparing our early childhood teacher education students to work with learners from diverse backgrounds and cultures, we wanted to examine a personal encounter between our students, as individual listeners to storytellers from different cultural and linguistic groups. Dewey (1938) spoke of teaching and learning as "a continuous process of reconstruction of experience", and Sommer, Derrick, Bourgeois, Ingene, Yang and Justice (2009) noted more specifically that experiential activities can support the development of multicultural understandings. The dialectical processes of experience and reflection on experience served as the conceptual framework for this study.

Through personal encounters with people identified as culturally and linguistically different from themselves, students had the opportunity to question their personal beliefs and values in light of the stories they heard. They were encouraged to examine their own multicultural awareness, and sensitivity, within the storytelling setting, while being asked to consider how it might affect their future teaching experiences. Therefore, by combining the use of storytelling from people whose home languages and cultures are different from those of our students, we believed that we could capture the impact of border crossing on students' understandings of the value of narrative, so as to broaden understandings of people in general and the children they would subsequently teach.

\section{Methodology}

This study took place at an urban university in South Africa where 129 students were enrolled in their final year of a four-year BEd degree programme in Foundation Phase teacher education. Students completing this course of study are qualified to teach from the Reception year (kindergarten) through to Grade 3. As part of the module students completed a storytelling assignment that included identifying a storyteller from a different cultural/linguistic group than the student, listening to an oral telling of a story 
from the storyteller's own experience or cultural background, and completing a written response to a guided reflection that was submitted with the completed project.

Of the 129 students enrolled in the module, 85 students completed the assignment in Afrikaans. They were all native Afrikaans speakers and identified themselves as Afrikaans South Africans. The remaining 41 students who comprised the 'Englishspeaking' group were all female South Africans, and included white Western European students, one Indian student, and three Black South African students whose first language was not English. To answer the question, "How can we strive to understand each other across the boundaries of culture, languages and other belief systems in SA?" we analysed the reflections of the 44 students who responded in English.

Ethically, permission for this project was obtained through the University's Ethical Clearance Committee. Both students' and storytellers' identities were kept confidential and all participants signed letters of informed consent to allow the use of the stories and reflections for analysis and publication.

Using a narrative inquiry approach (Charmaz, 2006) to understand storytelling as a vehicle for cultural border crossing, we coded each student reflection line by line to identify emerging themes. Once we independently coded all the reflections, we began to collapse the codes into broader themes and created memos to further explain the themes. We returned to the literature to check the veracity of the themes themselves, and the fit between the conceptual ideas we were identifying with the coded data.

\section{Findings}

What happened when students cross cultural borders to listen to stories told by members of different cultural and linguistic groups? According to our students, when they took the risk to ask someone to tell them a story, they found that their storytellers were eager to share information about themselves and relate stories that reflected their personal experiences, or that were part of their family or cultural heritage. The students learned that the stories told went beyond simply sharing information from storyteller to listener to become a conduit for teaching the students more about a culture, a language, and a person. As a result of the storytelling experience, students reported that new relationships were formed, or familiar relationships were deepened, and, as a result of their listening to others, they had a newfound respect for the storyteller and others more generally.

\section{Meeting at the border}

The essence of the storytelling encounter, the actual journey itself to meet another person through the shared experience of storytelling and listening, involves meeting at the border between the familiar and unfamiliar. This particular assignment pushed future teachers to become vulnerable in selecting storytellers who were different from themselves and this proved to be challenging for many. A few students selected family members, who were not English or Afrikaans, the dominant groups within 
the university. For these students, the level of risk taking to cross a cultural border was minimal. One student focused her attention on the storytelling aspect of the assignment and said,

I decided to use my Italian grandfather as the storyteller. As a child I would spend holidays with my grandfather, as he always had the best stories to tell. From ghost stories to war stories he always had a way to entertain and teach us something new.

Many students selected people who worked within their homes or residence halls as domestics, while others sought out people within the local community. For these students, approaching their potential storytellers was personally challenging, because now they had to ask 'favours' from people who typically provided services to them. Although the students felt vulnerable at having to "move outside their comfort zones" to identify a storyteller who met the criteria of the assignment, they found they were greeted enthusiastically by people who were willing to share their stories with them.

I also overcame personal fears, since I am a shy person who does not like asking anyone for help, therefore when I stepped out my comfort zone and found a willing participant; it was an experience of personal growth. I was rewarded with the satisfaction of enjoyment while I was listening to the story.

Many students identified people who were in their lives, but with whom they had never really talked before. In these more informal relationships, students were clearly in a more privileged position in their daily relationship with the storyteller. The storyteller was often a domestic worker in the student's home, or residence hall, or was a labourer in a service industry, such as a petrol attendant.

By speaking to someone who I have known for three years, but never really spoken to before was very rewarding and by listening to George I could see that he was excited that someone different was interested in his life!

I started working on it with my domestic worker, who I then realised has lived a very hard life in terms of trauma and heartbreak because of the story she chose to tell me. I also realised that I never really sit down and listen to her or ask her any questions about herself or about her life and how different it is to mine.

Given the differences in social position and class, the storytellers themselves might have felt vulnerable in sharing their personal stories with others, but for many, the opportunity to share with another person appeared to outweigh any concerns. All the students were able to find a person who would tell a story, but the students were the ones who were surprised at the willingness of the storytellers to share a personal event or a fictional story from their past.

I thought that no one would have the time or want to tell me their story. I found two people who worked at Sasol in my neighbourhood. They were eager to tell me their story [...] Sometimes, people from a lower demographic seemed to me illiterate. I found this not the case. Both my storytellers were excited to think back to their past and come up with a story.

The person I spoke to was so happy to tell me about these stories. He informed that the one he told me is merely a chapter from a whole set of stories that his family tell their young ones [...] Whilst watching him tell me the story I could see him truly taking a trip down memory lane to a place that held very beautiful memories to him [...] The security guards in my complex are always friendly and 
helpful and I chose to ask David because I felt he would be more appreciative than annoyed and I was correct.

\section{Seeing what is on the other side of the border}

The stories that we hear from others often teach us lessons about ourselves or about life. The storytellers in this study related stories of their own personal experiences, or from their own cultures. For example, Harry, one of the storytellers, told about a trip to the coast where his family had a lovely day at the beach that ended in sunburns. His story reinforced a common experience shared by many people regardless of culture, and served as a simple exchange one might have when meeting at the border. After hearing the story the student reflected:

This simply helped to teach me about the untold stories in the world and how every memory changes the way in which you will live from that point onwards. For example, Harry's whole family is very careful with their sun exposure since he remembers the pain his father endured from his sun burn. I am now reminded of the dangers of sun exposure and the fact that all experiences can have a positive and negative side to them.

Other stories served to teach the listeners about the different cultures and life experiences of the storytellers.

I introduced myself and he told me he was Johnny and that he is Sotho [...] He told me about their traditions in his family and their ways and beliefs. He explained the process of getting married which was a very important topic to him. He felt bad as he explained he's been married twice, once when he was twenty one, and then last year but is only expecting children from his new wife end of this year [...] He explained how in his culture the men have to save and bank money in order to show his chosen wife's father that he can support her and have children with her. Johnny explained that even once you are married you are still your family's child and therefore you do not have to make decisions on your own.

Still other stories invited the students into a world of fable and fantasy. When her storyteller told the tale of 'The lion and the donkey', the participant responded.

Sarah told me a folk tale, mostly told for entertainment and she was one of the best storytellers I have ever met. I learnt so much about the art of storytelling from this woman in the short time I spent with her, about capturing your audience and using your voice, it was wonderful.

Markham's story of the villagers' fear towards a blind woman's pet 'dog', an old retired circus lion, and their plot to dispose of the animal was spell-binding for the student who was listening.

When Markham started to tell me his story I was very curious as to how the story would turn out. I was even leaning forward out of interest. It made me realise how rare it is for people to tell each other stories in this generation. The wonder of storytelling is getting lost along with the rest of our youth's culture.

\section{Speaking the language}

However, when crossing cultural borders, you sometimes have to confront challenges related to language. Sometimes the linguistic challenges were very real for both 
the storyteller and the listener. Using gestures to assist in communicating with one another and telling stories was a common strategy shared by students and storytellers. However, it is interesting to note how unaware the students were of the language abilities of people they selected. For example, Lisa chose a domestic worker, of the family whose children she baby-sits, to be her storyteller. Prior to the assignment, neither knew each other well. The domestic worker was in her forties, while Lisa was in her early twenties. Lisa reported:I found this assignment to be a rather challenging one, as I encounter a few communication barriers such as the fact that Patricia's English is rather broken and I found that at most times she did not really understand me, even when I switched to Afrikaans to try and express myself in such a way that she could understand better, as that is her 'stronger language', I still had the feeling that she did not fully understand me. In a sense I felt that when I asked her about her biographical information and other interesting facts she held back.

Lisa discovered "that after this experience there is a better connection between us and now I find it easier to have every day conversations with her when I see her." Candice selected the domestic worker who had been employed by her mother since she was a young child. She commented:

Having Maxine around me all the time, I have never really realised her level of literacy. During our conversations of sharing information about our daily happenings I have never really realised her use of broken English. It had become a way of life and a norm for me. Through doing this assignment I realised actually how much she struggles to speak in English, but yet she tries so hard. Although her highest level of Education is Standard 8, she still struggles immensely with her English.

Regardless of their newfound opportunities for conversation that resulted from these encounters, the challenge of border crossing remains. Language structures the realities that are lived out within culture. The limitations, therefore, of a shared expressive and receptive language by both speaker and listener increases the possibility for miscommunication and misunderstanding.

Whether they knew their storytellers before the assignment or not, as students talked with their storytellers to learn more about them as people, and then listened to the stories that were told, they began to recognise their own misconceptions about others.

I did not know Salma before I started on this project; I knew that she occasionally worked at the house where I currently rent a room. I knew that she spoke beautiful Afrikaans and that; from the words I could recognise, she spoke Tswana, Sotho, or Pedi. I now realise that I quickly jumped to the ignorant conclusion that she would have difficulty telling me a grammatically correct story, or be able to write it down legibly. Salma is a remarkable woman. She is intelligent and funny with a permanently positive outlook on life. The wedding dresses that she makes are works of art, and should be displayed in boutiques.

But the encounter with different languages led many students to consider learning another language themselves.

After finishing this assignment I felt that I would like to try learning at least one different language besides English and Afrikaans, I started to wish that I had 
taken the subject Tswana more seriously in school but at that time my class and I saw it as a pointless subject as we would not be writing an exam on what we had learnt [...] I now know what it must feel like for a learner who does not understand English to go to school not understanding the language of medium in the school and then been expected to answer questions.

\section{Returning home}

After the time spent identifying a storyteller, getting to know the person and listening to the stories that were told, students reflected on what they had learned from their encounters with others. All of the students spoke of new, or enriched relationships, with their storytellers and a newfound appreciation for the diversity of cultures within South Africa.

By doing this assignment I now talk more to Leah and we often share stories of both her and my life and a connection between us has developed [...] I would not change anything about this assignment as I feel it was beneficial for me to take the time to learn about someone else especially someone who is from a different culture from myself and feel that it has changed me and I have grown personally as I now have a better understanding for another culture.

This assignment taught me a new type of respect for others. So often we believe that achieving success in life is through getting a degree, or owning a big house and getting married. Through doing the assignment it struck me once again that achieving success for one person can be completing different to achieving success for another person. For Miriam, success was rearing her baby to be a beautiful woman. Through hard work and dedication for her daughter she is now able to help her daughter to obtain a degree from a University in Financial Management. From Miriam growing up with nothing, she is determined to give her daughter a better life [... ] That is what I call success.

Border crossing into new spaces often means that we also have to learn a new culture and new way of being. Students spoke of learning about new cultures and the thinking behind the stories.

I found this assignment very interesting, as I was able to see how a person from another culture lived as a young child [...] As I grew up understanding Zulu and was exposed to the Zulu culture, it was interesting to see the differences and similarities between my own culture, Zulu and Sepedi. I think teachers of the younger grades should expose the learners to the different cultures of South Africa as it explains the multiculturalism of our country, which not all young learners are aware of.

\section{Conclusion}

How can we strive to understand each other across the boundaries of culture, languages and other belief systems in SA? Although the geography and nationality bind people together as South Africans, the richness of the 11 different languages and cultures and a history of segregation and suspicion continue to separate people. The common elements of stories and the universality of storytelling across generations and place serve to draw us together and allow us to transcend the boundaries of culture and language, class and status. Students in this study recognised that everyone has a story to tell, and if they moved from their comfort zones of familiarity they could 
appreciate the value of each person. This assignment opened a door for better understanding of cultural difference and led many students to consider learning more about other cultures and languages for themselves and for their future learners.

On the surface, the storytelling experience provided a context for storytellers and listeners to come together to share a tale. The students in this study expressed their interest in hearing the stories themselves, often mesmerised by the tale because of the way it was told or the content itself. However, what was clear from students' reflections was that the experience itself of being in relationship as a listener to a storyteller was the most significant aspect of the project. Regardless of the kind of story told - fable, imaginary, or experiential - students valued the opportunity to get to know others through their stories. The experience of telling and listening to stories created a cognitive and an affective bond between the storyteller and the audience, actively engaging both parties in new opportunities to increase self-reflection and enhance multicultural understandings through shared interpretations. As students listened to the stories of others they began to question their own personal experiences, beliefs and values, thereby opening doors to greater understanding of self and other leading to increased multicultural sensitivity. For some students, they recognised their positions of privilege compared to their storytellers. Even though they had known they had economic advantages over many people, they began to be more aware of their responsibility to listen with respect to others who had fewer economic resources and value the person as a unique individual who possessed different, yet important, assets. Other students empathised with their storytellers and were amazed at their resilience in the face of difficult life circumstances. Still others came to know people with whom they lived in new, more personal ways and their relationships began to shift to a deeper level of caring for one another.

In classrooms that are increasingly diverse in terms of students' home languages, cultures, abilities, and values, teachers must develop the multicultural understandings, skills, abilities, and dispositions to teach their learners. Ball (2006, p. 44-45) makes an important point in this regard when she says,

[...] listening to the narrative voices of our students can be a powerful tool for improving understanding, voiding stereotypes, reducing fear, and increasing familiarity with students' lived experiences outside school.

As a result of the assignment, students began to see that they had their own stories to tell and have, as a separate part of this larger project, written stories that they can use with Foundation Phase learners. Supporting Luwisch's (2001) findings that teachers who integrate their own stories into their curriculum may be more sensitive to their students' concerns, these students pointed to the power of knowing themselves and their ability to respectfully connect with others. The border crossings that were supported in this study suggest that when future teachers are able to meet another person from a different cultural and linguistic background through the medium of storytelling and listening, they can begin to approach 'otherness' with greater sensitivity and respect. 


\section{References}

Ball, A.F. (2006). Multicultural strategies for education and social change: Carriers of the torch in the United States and South Africa. New York: Teachers College Press.

Benjamin, B. (2006). The case study: Storytelling in the industrial age and beyond. On the Horizon, 14(4), p.159-164.

Carter, K. (1993). The place of story in the study of teaching and teacher education. Educational Researcher, 22(1), 5-12, 18.

Charmaz, K. (2006). Constructing grounded theory: A practical guide through qualitative analysis. Los Angeles: Sage.

Dewey, J. (1938). Experience and education. New York: Macmillan.

Doyle, W. \& Carter, K. (2003). Narrative and learning to teach: Implications for teachereducation curriculum. Journal of Curriculum Studies, 35(2), 129-137.

Langellier, K. \& Peterson, E. (2004). Storytelling in daily life: Performing narrative. Philadelphia, PA: Temple University Press.

Luwisch, F.E. (2001). Understanding what goes on in the heart and the mind: Learning about diversity and co-existence through storytelling. Teaching and Teacher Education, 17(2), 133-146.

Nieto, S. (1992). Affirming diversity: The socio-political context of multicultural education. New York: McGraw-Hill.

Percival, J.E. \& Black, D.J. (2000). A true and continuing story: Developing a culturally sensitive, integrated curriculum in college and elementary classrooms. The Social Studies, 91(4), 151-158.

Sax, B. (2006). Storytelling and the "information overload". On the Horizon, 14(4), 165-170.

Sommer, C.A., Derrick, E.C., Bourgeois, M.B., Ingene, D.H., Yang, J.W. \& Justice, C.A. (2009). Multicultural connections: Using stories to transcend cultural boundaries in supervision. Journal of Multicultural Counselling and Development, 37(4), 206-218. 